\title{
Regional Variation of Postjunctional $\alpha$ - Adrenoceptor Responses in the Developing Renal Vascular Bed of Sheep
}

\author{
G. PAUL MATHERNE, ${ }^{1}$ KENNETH T. NAKAMURA, ${ }^{2}$ BETH M. ALDEN, NANCY J. RUSCH, ${ }^{3}$ \\ AND JEAN E. ROBILLARD \\ Departments of Pediatrics and the Cardiovascular Research Center, University of Iowa College of Medicine, \\ Iowa City, IA 52242
}

\begin{abstract}
Postjunctional $\alpha_{1}$ - and $\alpha_{2}$-adrenoceptor vasoconstrictor responses were evaluated in isolated segments of main renal artery, segmental renal artery, and renal vein from fetal (130-138 d of gestation; term $145 \mathrm{~d}$ ), newborn (3-15 d age), and nonpregnant adult sheep. Vascular rings were mounted at their optimal resting tension and responses to phenylephrine ( $\alpha_{1}$-adrenoceptor agonist) and guanabenz and UK14304 (both $\alpha_{2}$-adrenoceptor agonists) were determined. Optimal resting tension increases with development in the main renal artery, segmental renal artery, and renal vein of sheep. Arterial vessels develop more isometric tension to $\alpha_{1}$-adrenoceptor stimulation than to $\alpha_{2}$-adrenoceptor stimulation, whereas venous segments develop similar isometric tension to $\alpha_{1}$ - and $\alpha_{2}$-adrenoceptor stimulation. The segmental renal artery develops more isometric tension to $\alpha_{2}$-adrenoceptor stimulation than the main renal artery. No large developmental differences exist among vessels in the sensitivity (concentration required for half maximal response, $\mathbf{E D}_{50}$ ) to $\alpha$-adrenoceptor stimulation except for the renal vein with $\alpha_{2}$-adrenoceptor stimulation. Maximum isometric tension corrected for vessel cross-sectional area decreases with age for all vessels with both $\alpha_{1}$ - and $\alpha_{2}$-adrenoceptor stimulation. These findings may reflect developmental differences in receptor number and affinity or differences in vascular smooth muscle function. In addition, these data suggest that whereas both $\alpha_{1-}$ and $\alpha_{2}$-adrenoceptors mediate vasoconstriction in the renal circulation, they may do so at different sites. (Pediatr Res 25:461-465, 1989)
\end{abstract}

\section{Abbreviations}

MRA, main renal artery

SRA, segmental renal artery

$R V$, renal vein

PE, phenylephrine

$\mathrm{Gb}$, guanabenz

UK, UK14304

$\mathrm{ED}_{50}$, concentration that produces half maximal response

Received June 10, 1988; accepted December 1, 1988

Correspondence to G. Paul Matherne, M.D., Assistant Professor, Department of Pediatrics, Division of Pediatric Cardiology, Box 386, University of Virginia Medical Center, Charlottesville. VA 22908.

Supported by USPHS Grants DK-38302, HD-20576, HL-14388, HD-35600. and HL-23081. K. T. N is the recipient of Clinical Investigator Award HD-00670. G. P. M is supported by NHLBI Training Grant HL-07413.

' Present address University of Virginia Medical Center, Department of Pediatrics, Division of Pediatric Cardiology, Box 386, Charlottesville, VA 22908.

${ }^{2}$ Present address Kapiolani Medical Center for Women and Children, Department of Pediatrics. John A. Burns School of Medicine, Honolulu, HI 96826.

${ }^{3}$ Present address Medical College of Wisconsin. Department of Physiology. Milwaukee. WI 53226
Recent studies in this laboratory have demonstrated that renal vascular $\alpha_{1}$-and $\alpha_{2}$-adrenoceptors are functional and can produce renal vasoconstriction in fetal sheep and newborn lambs (1) Moreover, the renal hemodynamic response to $\alpha_{1}$ - and $\alpha_{2}$-adrenoceptor stimulation changes during maturation with fetal and newborn $\alpha_{2}$-adrenoceptor responses less than those observed in adult sheep, whereas the $\alpha_{1}$-adrenoceptor responses were similar (1).

Contrary to our results (1), recent studies by Tayo et al. (2) using isolated vascular rings demonstrated that the $\alpha_{2}$-adrenoceptor-mediated contractile response is greater in 4- to 8-wk-old rabbits than in adult animals, suggesting that there may be a loss of $\alpha_{2}$-adrenoceptor-mediated contraction with maturation. Differences between the study by Tayo et al. (2) and our previous results (1) are difficult to explain. However, some of the differences between the two studies may be due to comparing in vivo experiments, where the overall hemodynamic response is studied. with in vitro experiments, where specific vascular segments are studied.

Therefore, the present study was designed to examine possible regional developmental differences in $\alpha_{1}$ - and $\alpha_{2}$-adrenoceptormediated vasoconstrictor responses in the developing renal vascular bed. Isolated segments of MRA, SRA, and RV from fetal. newborn, and nonpregnant adult sheep were studied.

\section{MATERIALS AND METHODS}

Animals. Vessels from seven fetal sheep (130-138 d of gestation; term $145 \mathrm{~d}$ ), seven newborn lambs (3-15 d of age), and seven nonpregnant adult sheep were evaluated using standard in vitro techniques (3). Gestational ages were determined as previously described (4)

Vessel preparation. Newborn and adult animals were killed with a lethal dose of intravenous pentobarbital. Pregnant ewes were anesthetized with a mixture of $1 \%$ halothane and $66 \%$ nitrous oxide and fetuses killed with pentobarbital injected into the umbilical vein. Segments of MRA, SRA, and RV were removed from each animal and immediately placed in cold Krebs solution (composition in $\mathrm{mM}$ ) $\mathrm{NaCl} 118, \mathrm{NaHCO}_{3} 25$, glucose $11, \mathrm{KCl} 4.7, \mathrm{Mg}_{2} \mathrm{SO}_{4} 1.2, \mathrm{CaCl}_{2} 2.2$, and disodium EDTA 0.025 (5). Vessels were cleared of adhering fat and connective tissue under a dissecting microscope with care taken to avoid stretching. Transverse rings were cut at 3- to 4-mm width for the MRA, 2to 3-mm width for the SRA, and 3- to 4-mm width for the RV. Segments of MRA were taken at least $3 \mathrm{~mm}$ distal to the origin of the MRA from the aorta and before the MRA branched outside the kidney. The SRA was taken from segments after the first intrarenal branching in the kidney which ran between the renal papillae. RV segments were taken from the main renal vein distal to branching outside the kidney and $2-3 \mathrm{~mm}$ proximal to the junction with the inferior vena cava. 
Rings were mounted by passing two fine, stainless steel wires through the vessel lumen. One side was anchored to a stationary rod and the other to a Grass FT.03 force-displacement transducer (Grass Instrument Co., Quincy, MA) connected to a Gould recorder (Gould Inc., Cleveland, $\mathrm{OH}$ ) for measurement of isometric force (3). The vascular rings were bathed in an organ bath filled with $25 \mathrm{~mL}$ Krebs solution at $39^{\circ} \mathrm{C}$ and gassed with $95 \%$ $\mathrm{O}_{2}-5 \% \mathrm{CO}_{2}$. After equilibration for $60 \mathrm{~min}$ with solution changed every $15 \mathrm{~min}$, each vascular ring was stretched to the optimal point on its length-tension curve as determined by $\mathrm{KCl}$ depolarization using 30-60 $\mathrm{mM} \mathrm{KCl}$ for the arterial vessels and $60-100$ $\mathrm{mM} \mathrm{KCl}$ for the venous vessels $(6,7)$.

All experiments were performed in the presence of desipramine $\left(10^{-5} \mathrm{M}\right)$ and hydrocortisone $\left(10^{-5} \mathrm{M}\right)$ to block neuronal and extraneuronal uptake of norepinephrine, respectively $(5,8)$. In addition, propranolol $\left(10^{-5} \mathrm{M}\right)$ was used to inhibit $\beta$-adrenergic receptors (8).

Experimental studies. Concentration-response curves to the $\alpha_{1}$-adrenoceptor agonist $\mathrm{PE}$, and the $\alpha_{2}$-adrenoceptor agonists $\mathrm{Gb}$ and $\mathrm{UK}$ were performed by cumulative increases in organ chamber concentration from $10^{-8} \mathrm{M}$ to $10^{-4} \mathrm{M}$ with $100 \mu \mathrm{L}$ additions of agonist to the bath. The concentration of drug was increased when the previous concentration had produced its maximal response. Prazosin $\left(10^{-6} \mathrm{M}\right)$, an $\alpha_{1}$-adrenoceptor antagonist, was added to the organ baths of vessels evaluated with $\alpha_{2^{-}}$ adrenoceptor agonists ( $\mathrm{Gb}$ or $\mathrm{UK}$ ) to exclude the potential for partial $\alpha_{1}$-adrenoceptor agonist activity $(2,9)$.

After each experiment, vessels were cut open and the circumference (c) and blotted wt (bw) were measured for calculation of cross-sectional area as determined by the equation:

$$
\mathrm{A}=\frac{2 \times \mathrm{bw}}{1.06 \times \mathrm{c}}
$$

where $A$ is the vessel cross-sectional area and 1.06 is the estimated tissue density in $\mathrm{g} / \mathrm{cm}^{3}(10)$. Normalizing isometric force for cross sectional area allows comparisons of responses from vessels of different sizes $(7,11,12)$.

Drugs. The following drugs were used: Gb (Wyeth Laboratories, Philadelphia, PA), UK (Pfizer, Sandwich, UK), prazosin (Pfizer, New York, NY), and L-PE, disodium EDTA, desipramine HCL, hydrocortisone, propranolol (all from Sigma Chemical Co., St. Louis, MO). Drugs were prepared daily in distilled water.

Calculations and statistical treatment. Baseline optimal resting tension was compared across ages and regions with Student's unpaired $t$ test and Bonferroni correction. Maximal tensions developed in $\mathrm{mN} / \mathrm{mm}^{2}$ were compared as follows: responses from MRA and SRA were compared across age groups and to each other for each agonist with 2-way ANOVA with Neuman Keuls multiple comparisons when differences were detected. RV responses were compared across age groups with 1-way ANOVA with Neuman Keuls multiple comparison when differences were detected. Maximal tension developed was compared between PE and $\mathrm{Gb}$ with Student's paired $t$ test and Bonferroni correction.

Mean values of $\mathrm{ED}_{50}$ (agonist concentration evoking half- maximal response) were calculated and statistically compared using the ALLFIT program (13-15). ALLFIT is a nonlinear least-square multiple-curve fitting program that allows simultaneous curve fittings of families of dose response curves based on the four parameter logistic equation:

$$
y=\frac{a-d}{1+(x / c)^{b}}+d
$$

where $y$ is the response; $x$, the arithmetic dose; $a$, the response when $\mathrm{x}=0$; $\mathrm{d}$, the response for "infinite" dose; $\mathrm{c}$, the $\mathrm{ED}_{50}$; and $\mathrm{b}$, the slope factor that determines the steepness of the curve. Goodness of fit of individual dose-response curves was evaluated by: 1) F ratio test, which represented the ratio of residual variance for one curve to the overall residual variance of the other curves, and 2) run test, which evaluated the randomness of distribution of data points around and along the fitted curve. Significant $F$ ratio tests $(p<0.05)$ or run tests $(p<0.05)$ suggested poor fits according to the logistic model. Consequences of forcing parameters to be equal were also evaluated by an $\mathrm{F}$ ratio test. A significant $p$ value $(<0.05)$ indicated that data supported the hypothesis that shared parameters were in fact different from each other (13). A significance level of $p<0.05$ was used for all statistical tests.

\section{RESULTS}

Baseline values. Optimal resting tension (Table 1 ) increased postnatally in all vessels ( $p<0.05$, unpaired $t$ test). Arterial vessels had greater optimal resting tension than veins at all ages and the MRA had greater optimal resting tension than the SRA in fetus and newborns $(p<0.05$, unpaired $t$ test).

ALLFIT analysis. Concentration response curves for every age, every vessel, and every agonist evaluated were appropriately fitted as evidenced by nonsignificant goodness of fit $F$ ratios and nonsignificant runs test using ALLFIT analysis (all $F$ ratio and runs tests $p>0.05$ ).

Effect of $\alpha_{1}$-adrenoceptor agonist PE on vascular contraction. Maximum isometric tension developed to PE showed an agedependent decrease for both MRA and SRA (Table 2) and RV (Table 3) ( $p<0.05$, ANOVA). In addition, the maximum response was greater in the MRA compared with the SRA at all ages $\left(p<0.05\right.$, ANOVA). When $\mathrm{ED}_{50}$ values were compared, fetal vessels were slightly though significantly more sensitive to PE than newborn vessels (Table 4) ( $p<0.05$, ALLFIT analysis).

Effect of $\alpha_{2}$-adrenoceptor agonist $G b$ on vascular contraction. Maximum isometric tension developed to $\mathrm{Gb}$ (in the presence of prazosin $10^{-6} \mathrm{M}$ ) also showed an age-dependent decrease for both arterial segments (Table 2) and RV (Table 3) $(p<0.05$, ANOVA). However, the maximum response for Gb was greater in the SRA compared with the MRA $(p<0.05$, ANOVA). The $\mathrm{Gb} \mathrm{ED}_{50}$ values for arterial vessels were similar across age groups (Table 4) ( $p>0.05$, ALLFIT analysis). The RV, by contrast, showed an age-dependent decrease in sensitivity to Gb-mediated $\alpha_{2}$-adrenoceptor stimulation ( $p<0.05$, ALLFIT analysis).

Effect of $\alpha_{2}$-adrenoceptor agonist $U K$ on vascular contraction. Maximum responses to UK (in the presence of prazosin $10^{-6} \mathrm{M}$ )

\begin{tabular}{|c|c|c|c|c|}
\hline & Fetus & Newborn & Adult & $\begin{array}{c}\text { Comparison } \\
\text { by age }\end{array}$ \\
\hline MRA & $\begin{array}{c}0.95 \pm 0.04 \\
(14)\end{array}$ & $\begin{array}{c}1.34 \pm 0.09 \\
\text { (13) }\end{array}$ & $\begin{array}{c}1.26 \pm 0.03 \\
(14)\end{array}$ & $\mathrm{F}<\mathrm{N}=\mathrm{A}$ \\
\hline SRA & $\begin{array}{c}0.61 \pm 0.03 \\
(14)\end{array}$ & $\begin{array}{c}0.82 \pm 0.02 \\
\quad(13)\end{array}$ & $\begin{array}{c}1.19 \pm 0.04 \\
(14)\end{array}$ & $\mathrm{F}<\mathrm{N}<\mathrm{A}$ \\
\hline Comparison by vessel & $\begin{array}{c}0.14 \pm 0.01 \\
(12) \\
\mathrm{RV}<\mathrm{SRA}<\mathrm{MRA}\end{array}$ & $\begin{array}{c}0.27 \pm 0.04 \\
(12) \\
\mathrm{RV}<\mathrm{SRA}<\mathrm{MRA}\end{array}$ & $\begin{array}{c}0.21 \pm 0.01 \\
(13)\end{array}$ & $F<N=A$ \\
\hline
\end{tabular}

Table 1. Optimal resting tension (expressed in $g$ )* correction). 
REGIONAL VARIATION OF RENAL $\alpha$-VASOCONSTRICTION

Table 2. Maximum contractile response of renal arteries to $P E, G b$, and $U K\left(\mathrm{mN} / \mathrm{mm}^{2}\right)^{*}$

\begin{tabular}{|c|c|c|c|c|c|c|c|c|}
\hline & \multicolumn{3}{|c|}{ MRA $\dagger$} & \multirow{2}{*}{$\begin{array}{l}\text { MRA age } \\
\text { comparison }\end{array}$} & \multicolumn{3}{|c|}{ SRA } & \multirow{2}{*}{$\begin{array}{l}\text { SRA age } \\
\text { comparison }\end{array}$} \\
\hline & Fetus & Newborn & Adult & & Fetus & Newborn & Adult & \\
\hline PE & $13.1 \pm 2.5 \neq$ & $9.8 \pm 2.1 \ddagger$ & $3.8 \pm 0.6 \pm$ & $F>N>A$ & $11.0 \pm 2.2 \neq$ & $4.7 \pm 1.2 \ddagger$ & $2.0 \pm 0.2$ & $F>N>A$ \\
\hline $\mathrm{Gb}$ & $2.4 \pm 0.4$ & $0.4 \pm 0.1$ & $0.4 \pm 0.1$ & $F>N=A$ & $3.1 \pm 0.5$ & $1.5 \pm 0.8$ & $1.6 \pm 0.2$ & $F>N=A$ \\
\hline UK & $1.0 \pm 0.1$ & $0.3 \pm 0.2$ & $0.2 \pm 0.04$ & $\mathrm{~F}>\mathrm{N}=\mathrm{A}$ & $1.9 \pm 0.2$ & $0.6 \pm 0.1$ & $0.4 \pm 0.2$ & $\mathrm{~F}>\mathrm{N}=\mathrm{A}$ \\
\hline
\end{tabular}

$*$ Values are means \pm SEM; all $n=7$. $>$, difference when $p<0.05$ (2-way ANOVA and Newman-Keuls comparison).

$\uparrow$ All MRA different from SRA at $p<0.05$ (2-way ANOVA and Newman-Keuls comparison).

$\ddagger \mathrm{PE}$ different from $\mathrm{Gb}$ at $p<0.05$ (paired $t$ test).

Table 3. Maximum contractile response of renal veins to $P E$, $\mathrm{Gb}$, and $U K\left(\mathrm{mN} / \mathrm{mm}^{2}\right)^{*}$

\begin{tabular}{ccccc}
\hline & Fetus & Newborn & Adult & $\begin{array}{c}\text { Age } \\
\text { comparison }\end{array}$ \\
\hline & & & & $N$ \\
PE & $1.6 \pm 0.3$ & $1.2 \pm 0.2$ & $0.3 \pm 0.1$ & $\mathrm{~F}=\mathrm{N}>\mathrm{A}$ \\
& $(7)$ & $(7)$ & $(7)$ & \\
Gb & $1.6 \pm 0.3$ & $0.6 \pm 0.1$ & $0.1 \pm 0.03$ & $\mathrm{~F}>\mathrm{N}=\mathrm{A}$ \\
& $(7)$ & $(7)$ & $(7)$ & \\
UK & $1.9 \pm 0.2$ & $0.8 \pm 0.2$ & $0.1 \pm 0.1$ & $\mathrm{~F}>\mathrm{N}>\mathrm{A}$ \\
& $(5)$ & $(6)$ & $(6)$ & \\
\hline
\end{tabular}

* Values are means \pm SEM. Numbers in parentheses are number of observations. $>$, difference when $p<0.05$ (1-way ANOVA and NewmanKeuls comparison). PE responses not different from $\mathrm{Gb}$ responses $p>$ 0.05 (paired $t$ test).

Table 4. $E D_{50}$ (molar)*

\begin{tabular}{lccc}
\hline & $\mathrm{PE}$ & $\mathrm{Gb}$ & $\mathrm{UK}$ \\
\hline MRA & & & \\
$\quad$ Fetus & $2.2 \pm 0.2 \times 10^{-5}$ & $2.5 \pm 0.4 \times 10^{-5}$ & $0.9 \pm 0.2 \times 10^{-6}$ \\
Newborn & $3.6 \pm 0.3 \times 10^{-5}$ & $2.1 \pm 0.4 \times 10^{-5}$ & $6.2 \pm 1.9 \times 10^{-6}$ \\
Adult & $3.3 \pm 0.3 \times 10^{-5}$ & $2.0 \pm 0.4 \times 10^{-5}$ & $7.2 \pm 1.3 \times 10^{-6}$ \\
& $\mathrm{~F}<\mathrm{N}=\mathrm{A}$ & $\mathrm{F}=\mathrm{N}=\mathrm{A}$ & $\mathrm{F}<\mathrm{N}=\mathrm{A}$ \\
SRA & & & \\
Fetus & $1.5 \pm 0.2 \times 10^{-5}$ & $0.7 \pm 0.1 \times 10^{-5}$ & $0.6 \pm 0.1 \times 10^{-6}$ \\
Newborn & $3.1 \pm 0.3 \times 10^{-5}$ & $1.2 \pm 0.3 \times 10^{-5}$ & $0.8 \pm 0.1 \times 10^{-6}$ \\
Adult & $2.3 \pm 0.4 \times 10^{-5}$ & $1.3 \pm 0.3 \times 10^{-5}$ & $1.5 \pm 0.2 \times 10^{-6}$ \\
& $\mathrm{~F}<\mathrm{N}, \mathrm{N}=\mathrm{A} . \mathrm{F}=\mathrm{A}$ & $\mathrm{F}=\mathrm{N}=\mathrm{A}$ & $\mathrm{F}=\mathrm{N}<\mathrm{A}$ \\
RV & \multicolumn{4}{c}{} \\
Fetus & $1.1 \pm 0.1 \times 10^{-5}$ & $5.0 \pm 0.8 \times 10^{-8}$ & $0.9 \pm 0.1 \times 10^{-7}$ \\
Newborn & $1.9 \pm 0.2 \times 10^{-5}$ & $2.9 \pm 0.7 \times 10^{-7}$ & $3.4 \pm 0.3 \times 10^{-7}$ \\
Adult & $1.2 \pm 0.1 \times 10^{-5}$ & $4.6 \pm 1.4 \times 10^{-6}$ & $1.9 \pm 0.2 \times 10^{-7}$ \\
\multicolumn{2}{c}{$\mathrm{F}=\mathrm{A}<\mathrm{N}$} & $\mathrm{F}<\mathrm{N}<\mathrm{A}$ & $\mathrm{F}<\mathrm{A}<\mathrm{N}$ \\
\hline
\end{tabular}

$*$ Values are means \pm SEM, number of observations for each vessel, age. and agonist combination may be found in Tables 2 and $3 .<$, difference when $p<0.05$ (ALLFIT analysis).

were similar to $\mathrm{Gb}$ responses, with age-related decreases in both arterial (Table 2) and venous segments (Table 3) $(p<0.05$, ANOVA). The maximum response to UK was also greater in the SRA compared with the MRA ( $p<0.05$, ANOVA). The $\mathrm{ED}_{50}$ values for UK show small age-dependent decreases in sensitivity for both arterial and venous segments (Table 4) $(p<$ 0.05 , ALLFIT analysis).

Comparison of $\alpha_{1}$-and $\alpha_{2}$-adrenoceptor-mediated contractions. The maximum response to $\mathrm{PE}$ was greater than the maximum response to $\mathrm{Gb}$ in the MRA for all ages (Table 2) $(p<0.05$, paired $t$ test). In the SRA, the PE response was greater than the $\mathrm{Gb}$ response in the fetus and newborn (Table 2$)(p<0.05$, paired $t$ test). A typical experimental tracing from a fetus (Fig. 1A) demonstrates the greater magnitude of the PE response compared with the $\mathrm{Gb}$ response in arterial vessels. In the RV, by contrast, the maximum response to $P E$ was not different from the maximum response to $\mathrm{Gb}$ (Table 3$)(p>0.05$, paired $t$ test) and is illustrated by a typical experimental tracing in Figure $1 B$.
A MRA

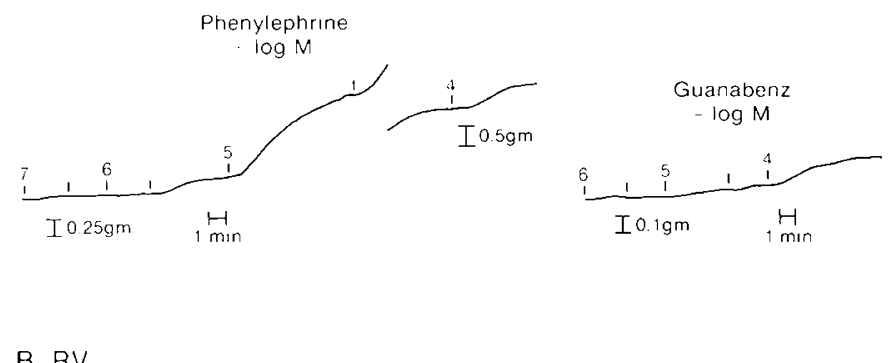

B RV

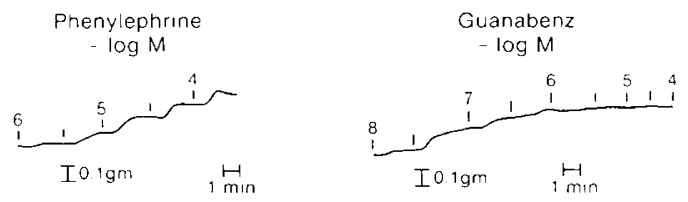

Fig. 1. Isometric tension recordings from segments of MRA in $A$ and in segments of RV in $B$ from a fetal sheep. Responses of the MRA to phenylephrine are much greater than the response to $\mathrm{Gb}(A)$, whereas $\mathrm{PE}$ and $\mathrm{Gb}$ responses are similar in the RV $(B)$.

\section{DISCUSSION}

The isolated vessel technique used in the present study is a suitable method for examining responses of different regions within a vascular bed and has several distinct advantages. The confounding effects of circulating vasoactive substances, central neural control, and local metabolic control present in vivo are all avoided. As such, intrinsic receptor and smooth muscle characteristics of a particular vascular segment can be studied. However, the microcirculation cannot be easily evaluated.

We found age-dependent increases in optimal resting tension (Table 1), supporting observations of Pagani et al. in sheep aortas (16) and Cox et al. in canine arteries (17), who found that arterial stiffness increases with age. However, it contrasts with the findings of Seidel et al. (7), who found no developmental changes in optimal resting tension in canine arteries and veins. Most of the differences we observed, however, were between prenatal and postnatal vessels which were not compared in the study by Seidel et al. (7). Changes in optimal resting tensions with age may reflect alterations in physical characteristics of the vessels (18); however, these properties were not the focus of the present investigation.

The finding that arterial vessels develop more isometric tension to $\alpha_{1}$-adrenoceptor stimulation than to $\alpha_{2}$-adrenoceptor stimulation (Table 2) has been previously reported (19-22), although no studies have examined pre- and postnatal differences. One possible explanation for smaller $\alpha_{2}$-adrenoceptor mediated vaso-. constriction may be that the receptors are located on small "resistance" vessels rather than larger vessels $(20,23,24)$. Our finding that the maximum response to Gb and UK in the SRA was greater than the response in the MRA suggests an increased ability to respond to $\alpha_{2}$-adrenoceptor stimulation in smaller arterial vessels. This finding is consistent with results from Muntz et al. (24) and Faber (23) who found increased $\alpha_{2}$-adrenoceptor 
receptors and function on arterioles. Our results, however, provide only supportive evidence for the hypothesis of increased $\alpha_{2}$ adrenoceptors on smaller arterial vessels since receptor numbers and location were not determined. Another theory, offered by Ruffolo (22), is that $\alpha_{1}$ - and $\alpha_{2}$-adrenoceptors have different "receptor-effector coupling" and $\alpha_{2}$-adrenoceptors may become "uncoupled" from their effector mechanisms when removed for in vitro studies. However, the present study was not designed to study this aspect.

In contrast, the maximum responses for $\mathrm{PE}$ and $\mathrm{Gb}$ were similar to each other in the RV (Table 3 ). The present results support previous data that $\alpha_{2}$-adrenoceptor responses are prominent in the venous circulation, consistent with the hypothesis that postsynaptic vascular $\alpha_{2}$-adrenoceptors may play a more important functional role in the venous relative to arterial circulation $(19,22,25)$. Thus, one may speculate that during fetal life, renal venous circulation may be controlled, in part, by postsynaptic $\alpha_{2}$-adrenoceptor vasoconstrictor tone. The role of venous tone in modifying overall renal hemodynamics is an intriguing concept that awaits further investigation.

Earlier results comparing sensitivity of the vasculature to $\alpha$ adrenergic stimulation during development have been conflicting $(7,11,18,26,27)$. Gray (27) found that neonatal canine aortic strips had higher $\mathrm{ED}_{50}$ values for $\mathrm{PE}$ and norepinephrine than mature dogs, while Cohen and Berkowitz (11) found that young rat aortas had a lower $\mathrm{ED}_{50}$ for norepinephrine than older rats. Seidel et al. (7) found no change in the $\mathrm{ED}_{50}$ for PE in most vessels in the developing dog. Our findings (Table 4) show a small, although at times statistically significant, age-related decrease in sensitivity to all agonists. It is important to note, however, that the physiologic significance of these small differences in $\mathrm{ED}_{50}$ may be questioned since most differences were much less than one half log unit. An exception was the renalvein response to $\mathrm{Gb}$ which showed large age-related decreases in sensitivity. The reasons our findings are different from previous studies are not clear although species differences and regional variations could explain the dissimilarities.

For all ages, vessels, and agonists studied, we found agedependent decreases in maximum isometric tension developed after correction for vessel cross-sectional area (Tables 2 and 3). Similar results were found by Park and Sheridan (28), using phenylephrine to contract guinea pig and rabbit aortas, and by Toda et al. (12), using norepinephrine to contract canine cerebral vessels. Gray (27), on the other hand, found age-dependent increases in maximum tension developed to norepinephrine and $P E$ in aortic strips from dogs but the data were not normalized for cross-sectional area. Finally Seidel et al. (7) showed increasing maximal tension to $\mathrm{PE}$ with maturation using a variety of canine vessels including the renal artery, suggesting that vessels from sheep compared to dogs appear to have different developmental characteristics.

The findings of developmental decreases in maximal isometric tension in vitro contrast our in vivo data (1), which showed developmental increases in $\alpha_{2}$-adrenoceptor vasocontriction and similar $\alpha_{1}$ responses at low levels of stimulation. Differences between the in vivo and in vitro data may relate to differences in the integrative response of the intact renal vascular bed compared with the isolated vessel response. In addition, the contribution of arterioles and venules in control of renal hemodynamics in vivo may be significant.

Reasons for the decrease in maximal isometric tension with age were not investigated in our study. Pearce and Ashwal (29) found results similar to ours in the carotid artery using $\mathrm{KCl}$ depolarization and attributed the decrease in maximum tension developed to the thicker arterial wall found in the mature animal. The thicker wall is thought to be due to more increases in collagen and elastin than contractile proteins $(18,30)$. Whether our results are secondary to similar structural changes, differences in receptor characteristics or number, or differences in smooth muscle characteristics such as actin and myosin content and calcium utilization, remains to be defined.

In summary, the present study demonstrates that: 1 ) optimal resting tension increases postnatally in the renal vascular bed of sheep; 2) renal arterial vessels develop more isometric tension to $\alpha_{1}$-adrenoceptor stimulation than to $\alpha_{2}$-adrenoceptor stimulation; 3) renal venous segments develop similar isometric tension to $\alpha_{1}{ }^{-}$and $\alpha_{2}$-adrenoceptor stimulation; 4) the SRA develops more isometric tension to $\alpha_{2}$-adrenoceptor stimulation than the MRA; 5) no large developmental differences were found in the sensitivity of the vessels to $\alpha$-adrenoceptor agonists except for the RV which became less sensitive to Gb during maturation; 6) maximum isometric tension corrected for vessel cross-sectional area decreases with age for all vessels and all agonists. These findings may reflect developmental differences in receptor number and affinity or may reflect developmental changes in vascular smooth muscle function. In addition, the data suggest that distribution of postsynaptic $\alpha$-adrenoceptor subtypes that mediate renal vasoconstriction vary within the renal vascular bed during development. One may speculate that $\alpha_{1}$ - and $\alpha_{2}$-adrenoceptor agonists may both produce decreases in renal blood flow, but may be acting predominantly at different sites within the renal circulation.

Acknowledgment. The authors appreciate the secretarial assistance of Ruth Hurlburt, and generous supplies of $\mathrm{Gb}$ from Wyeth Laboratories, Philadelphia, PA; prazosin from Pfizer Laboratories, New York, NY; and UK from Pfizer Limited, Sandwich, UK.

\section{REFERENCES}

1. Matherne GP, Nakamura KT, Robillard JE 1988 Ontogeny of $\alpha$-adrenoceptor responses in renal vascular bed of sheep. Am J Physiol (Regulatory Integrative Comp Physiol 23) 254:R277-R283

2. Tayo FM, Bevan RD, Bevan JA 1986 Changes in postjunctional $\alpha$-adrenoceptors during postnatal growth in rabbit arteries. Circ Res 58:867-873

3. Bevan JA, Osher JV 1972 A direct method for recording tension changes in the wall of small blood vessels in vitro. Agents Actions 2:257-260

4. Jennings JJ, Crowley JP 1972 The influence of mating management on fertility in ewes following progesterone-PMS treatment. Vet Rec 90:496-498

5. Furchgott RF 1972 The classification of adrenoceptors (adrenergic receptors) an evolution from the standpoint of receptor theory. In: Blashko H, Muscholl E (eds) Handbook of Experimental Pharmacology, vol 33, New York, Springer-Verlag, pp 283-335

6. Vanhoutte P, Leusen I 1969 The reactivity of isolated venous preparations to electrical stimulation. Pflugers Arch 306:341-353

7. Seidel CL, Ross B, Michael L, Freedman J, Burdick B, Miller T 1987 Maturational changes in the pharmacological characteristics and actomyosin content of canine arterial and venous tissue. Pediatr Res 21:152-158

8. Green RS, Leffler CW 1984 A comparison of the sensitivities of neonatal ovine pulmonary and femoral arteries to L-norepinephrine stimulation. Pediatr Res 18:244-247

9. Thom S, Hayes R, Calvete J, Sever PS 1985 In vivo and in vitro studies of $\alpha_{2}$ adrenoceptor responses in human vascular smooth muscle. J Cardiovasc Pharmacol 7:S137-S143

10. Paul RJ 1983 The effects of isoproterenol and ouabain on oxygen consumption, lactate production and the activation of phosphorylase in coronary artery smooth muscle. Circ Res 52:683-690

11. Cohen ML, Berkowitz BA 1976 Vascular contraction: effect of age and extracellular calcium. Blood Vessels 13:139-154

12. Toda N, Shimizu I, Okamura T, Miyazaki M 1986 Age-dependent change in the response of isolated beagle cerebral arteries to vasoactive agents. J Cardiovasc Pharmacol 8:681-688

13. Delean A, Munson PJ, Rodbard D 1978 Simultaneous analysis of families of sigmoidal curves: application to bioassay, radioligand assay, and physiological dose-response curves. Am J Physiol 253:E97-E102

14. Rubanyi G, Paul RJ $1984 \mathrm{O}_{2}$-sensitivity of beta adrenergic responsiveness in isolated bovine and porcine coronary arteries. J Pharmacol Exp Ther 230:692-698

15. Nakamura KT, Matherne GP, Jose PA, Alden BM, Robillard JE 1988 Effects of epinephrine on the renal vascular bed of fetal, newborn, and adult sheep. Pediatr Res 23:181-186

16. Pagani M, Mirsky I, Baig H, Manders WT, Kerkhof P, Vatner SP 1979 Effects of age on aortic pressure-diameter and elastic stiffness-stress relationships in unanesthetized sheep. Circ Res 44:420-429

17. Cox RH, Jones AW, Fischer GM 1974 Carotid artery mechanics, connective tissue and electrolyte changes in puppies. Am J Physiol 227:563-568 
18. Duckles SP, Banner W Jr. 1984 Changes in vascular smooth muscle reactivity during development. Annu Rev Pharmacol Toxicol 24:65-83

19. DeMey J, Vanhoutte PM 1981 Uneven distribution of alpha- $I$ and alpha-2 like adrenoceptors in canine arterial and venous smooth muscle. Circ Res 48:875-884

20. McGrath JC 1982 Evidence for more than one type of postjunctional $\alpha$ adrenoceptor. Biochem Pharmacol 31:467-484

21. Polonia JJ, Paiva MQ, Guimaraes S 1985 Pharmacological characterization of postsynaptic $\alpha$ adrenoceptor subtypes in five different dog arteries in vitro. J Pharm Pharmacol 37:205-208

22. Ruffolo RR Jr 1986 Spare $\alpha$-adrenoceptors in the peripheral circulation: Ruffolo RR Jr 1986 Spare $\alpha$-adrenoceptors in the peripher.
excitation-contraction coupling. Fed Proc 45:2341-2346

23. Faber JE 1988 In situ analysis of $\alpha$-adrenoceptors on arteriolar and venular smooth muscle in rat skeletal muscle microcirculation. Circ Res 62:37-50

24. Muntz KH, Meyer L, Gadol S, Calianos TA 1986 Alpha-2 adrenergic receptor localization in the rat heart and kidney using autoradiography and tritiated rauwolscine. J Pharmacol Exp Ther 236:542-547

25. Ruffolo RR Jr 1985 Distribution and function of peripheral $\alpha$-adrenoceptors in the cardiovascular system. Pharmacol Biochem Behav 22:827-833

26. Fleisch JH 1980 Age-related changes in the sensitivity of blood vessels to drugs. Pharmacol Ther 8:477-487

27. Gray SD 1977 Reactivity of neonatal canine aortic strips. Biol Neonate 31:1014

28. Park MK, Sheridan PH 1979 Alpha- and beta-adrenergic mechanisms in the aorta of newborn rabbits and guinea pigs. Gen Pharmacol 10:257-261

29. Pearce WJ, Ashwal S 1987 Developmental changes in thickness, contractility, and hypoxic sensitivity of newborn lamb cerebral arteries. Pediatr Res 22:192-196

30. Cox RH, Jones AW, Swain ML 1976 Mechanics and electrolyte composition of arterial smooth muscle in developing dogs. Am J Physiol 231:77-83 